\title{
Contemporary Crises and Sustainability Indicators
}

\author{
Aleksander Zidanšek ${ }^{1,2}$, Marko Limbek ${ }^{3}$, Ivo Šlaus ${ }^{* 4,5}$ \\ ${ }^{1}$ Jožef Stefan International Postgraduate School, \\ Jožef Stefan Institute, Ljubljana, Slovenia \\ ${ }^{2}$ Faculty of Natural Sciences and Mathematics, \\ University of Maribor, Slovenia \\ ${ }^{3}$ Episcenter, Ljubljana, Slovenia \\ ${ }^{4}$ Ruđer Bošković Institute, Zagreb, Croatia \\ ${ }^{5}$ Dag Hammarskjold University College of International Relations and Diplomacy, Zagreb, Croatia \\ e-mail: slaus@irb.hr
}

Cite as: Zidanšek, A., Limbek, M., Šlaus, I., Contemporary Crises and Sustainability Indicators, J. sustain. dev. energy water environ. syst., 2(2), pp 100-107, 2014, DOI: http://dx.doi.org/10.13044/j.sdewes.2014.02.0009

\begin{abstract}
Following six decades of fastest economic and technological development in history, the current crises have been triggered by collapse of unsustainable financial systems. The extent of these contemporary interconnected crises of economic, societal, environmental, financial and other systems has also shown a need to reevaluate the measurement of sustainable development. Although the existing sustainability indicators are very complex, interdisciplinary and multidimensional, they could neither predict the onset of the crises nor their extent. Therefore relations between indicators of sustainability, technological development and happiness are presented and discussed also in terms of some of the current crises. Some possible solutions are also presented, which could be used for better measurement of life quality and could potentially replace the Gross Domestic Product as the prevailing measure of development.
\end{abstract}

\section{KEYWORDS}

Crisis, Sustainability indicators, Happiness, Life satisfaction, Technology indicators

\section{INTRODUCTION}

There are many theories on the origin of current crises. There is however no coherent and realistic plan for overcoming these crises in a sustainable manner. Therefore there exists a need to re-evaluate the indicators of development, sustainable development and quality of life in such a way that could contribute toward sustainable solutions of the contemporary crises.

There have been many attempts to create a widely accepted measure of sustainable development, such as the initiative of Yale Center for Environmental Law \& Policy to create the Environmental Sustainability Index [1] and the Environmental Performance Index [2].

While these and similar indices have been widely used, they failed to achieve significant influence on global development. All these indices are designed as a composite measure, which strongly depends on the selection of individual indicators and their weights. As these weights depend on values, it is very difficult to create an objective

\footnotetext{
* Corresponding author
} 
methodology that would lead to an objective measure of sustainability. All these indices are therefore at least somehow subjective.

In recent years there has also been significant progress in the study of subjective indicators [3]. These indicators directly measure life satisfaction, happiness or another subjective measure that is obtained from questionnaires with significant statistics.

Some correlations and interdependence of sustainability indicators and subjective measures of development have been studied in recent years such as the relationship between sustainability and happiness [4] based on the Veenhoven's database of happiness [5].

Recent crises have also been characterized by the economic slowdown accompanied by the rise in unemployment and many times also by lack of funding for education, research and healthcare in many countries.

The current crisis is the latest occurrence of periodic crises that characterised economic development in the past centuries. Already Schumpeter suggested in the 1930's that there exist long-term economic cycles [6] such as Kondratieff cycle [7] of the length between 45 and 60 years. Korotayev et al. [8] for example confirmed in global GDP data from 1870-2007 the presence of Kondratieff cycles with a period about 52 years.

These cycles could originate either from investment cycles [8], demographic processes [9] or other factors. Cycles could for example be observed from the well-known time dependence of the world GDP per capita [10] (Fig. 1).

\section{World GDP per capita}

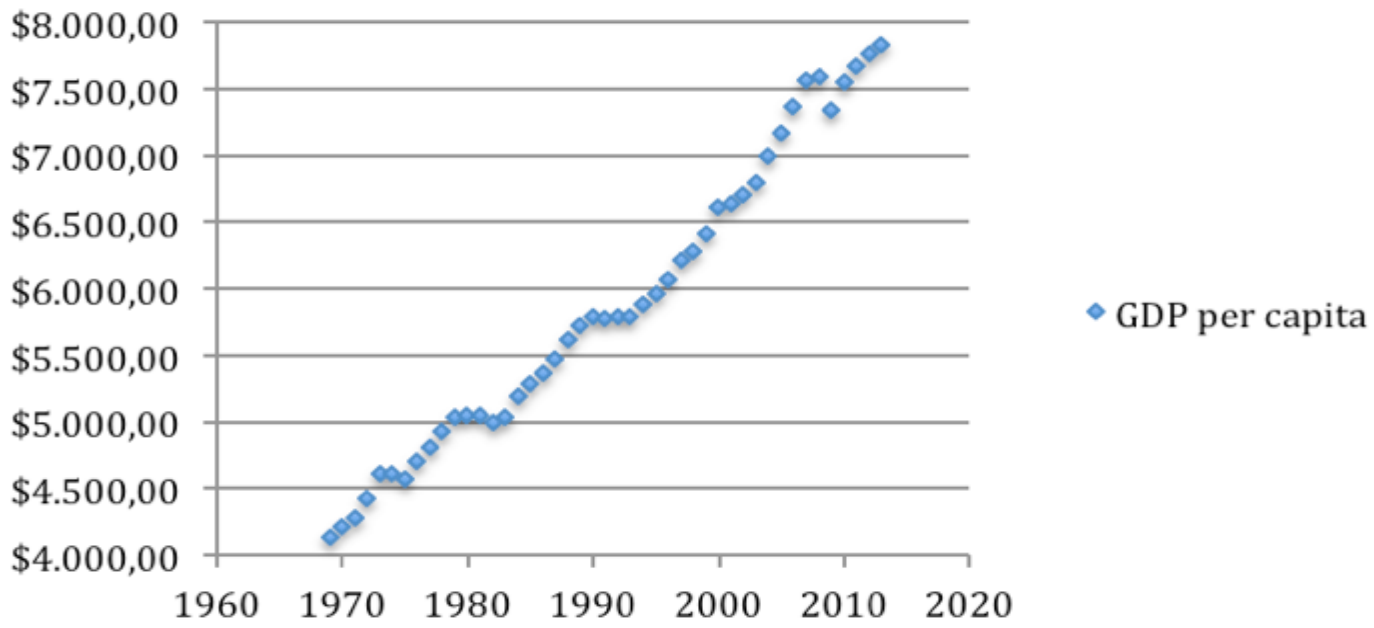

Figure 1. World gross domestic product (GDP) per capita in 2005 USD since 1969 [10]

\section{METHODOLOGY}

We present some subjective measures of life quality and of technological development as well as their relations to the sustainability indicators. Special emphasis is placed on indicators with an ability to replace the gross domestic product (GDP) as the dominant measure of development. We also analyze the consequences of the lack of leadership that was in many countries even more pronounced because of the disconnection of the so-called political class from the people [11].

Happiness is an interesting subjective indicator, which is measured by a large-scale questionnaire where people rate their happiness on a numerical scale [5]. Although this 
measure is very subjective and strongly depends on time for each individual person, large-scale averages are rather stable and produce interesting results. Researchers have found that there exists a personal genetic set point of happiness, which accounts for about $50 \%$ of happiness, and that environment accounts for about $10 \%$ of happiness. There is also an additional contribution of $40 \%$, which is not related to genetics or environment [12].

There have also been many attempts to study relation between happiness and sustainability. There is obviously a positive correlation between the two sets of indices, which is however strongly modified by the cultural and other influences [4]. An example of a combined index was designed by the New Economics Foundation in 2009 as the Happy Planet Index [13]. Although this index provides some interesting insight, the contributions of sustainability and happiness are mixed into a weighted average that is difficult to relate with something relevant to individual person's life. Happiness in nations index of a country as an average of the individual happiness as reported in questionnaires [5] has the advantage that it is directly related to individual happiness in a similar way as the Gross National Income (GNI) in related to individual personal income. Based on the principle of greatest happiness developed by philosopher Jeremy Bentham, which states the greatest happiness of the greatest number is the foundation of morals and legislation [14], happiness index could be an excellent measure of development. Although it is positively correlated to most of the contemporary indices of development, its main obstacle is a lack of large scale and regular systematic measurements. While GNI can easily be measured on a monthly basis, the happiness index is usually only measured on a small part of population every few years. A more regular measurement of happiness could be introduced with a new democratic paradigm, where the decision-making would shift from political elites to citizens [11].

It is well known that GDP and happiness are positively correlated, and that this correlation is strongest for low income with annual GDP below about 10,000 USD per capita [15]. Kahneman and Deaton have also shown that the positive effect of GDP on emotional wellbeing is reduced with increasing income, however that the positive effect of GDP on subjective evaluation of life is not reduced even for incomes above 10,000 USD per month [16].

\section{RESULTS AND DISCUSSION}

Table 1 presents selected correlations between indicators of sustainability, happiness, life satisfaction and technological development. Here two indicators describe sustainability, ESI [1] and EPI [2]. Two subjective measures include Life Satisfaction Indicator (SATIS) and Happiness in Nations Indicator (HAPPY) [17]. The third group of indicators are various measures of technological development from the International Telecommunication Union [18]. Correlations between pairs of indicators have been calculated for countries where measurements of both indicators exist. The number of countries in each pair is given next to the obtained Pearson correlation coefficient.

This analysis demonstrated that there is a positive correlation between the three groups, namely sustainability, subjective measures and technological development. All the observed correlations but one are positive, and many are strongly significant. The only negative correlation is between Happiness in Nations and Percentage of households with radio, which is calculated on a small sample of only 32 countries, and is therefore not very reliable. Both sustainability indicators ESI and EPI are strongly positively correlated, and the same is true for both subjective indicatros, namely Happiness in Nations and Life Satisfaction. Both EPI and ESI are strongly positively correlated with indicators of technological development with 9 respectively 8 strong correlations of 12 observed pairs. There are some subtle differences between Happiness in Nations and Life Satisfaction, which are both positively correlation with indicators of sustainability as well as with 
indicators of technological development. However, the correlations of Life Satisfaction with these two groups of indicators is slightly stronger than those of Happiness in Nations. Both get 6 strong positive correlations of 12 observed pairs.

Of the 12 technological indicators, the 5 indicators related to internet and computers have strongest correlations with the other two groups.

Table 1. Correlations between selected indicators

\begin{tabular}{|c|c|c|c|c|c|c|c|c|}
\hline & $\begin{array}{l}\text { Pearson } \\
\text { correlation } \\
\text { coefficient }\end{array}$ & $\begin{array}{c}\text { Number } \\
\text { of } \\
\text { compared } \\
\text { countries }\end{array}$ & $\begin{array}{l}\text { Pearson } \\
\text { correlation } \\
\text { coefficient }\end{array}$ & $\begin{array}{c}\text { Number } \\
\text { of } \\
\text { compared } \\
\text { countries }\end{array}$ & $\begin{array}{c}\text { Pearson } \\
\text { correlation } \\
\text { coefficient }\end{array}$ & $\begin{array}{c}\text { Number } \\
\text { of } \\
\text { compared } \\
\text { countries }\end{array}$ & $\begin{array}{l}\text { Pearson } \\
\text { correlation } \\
\text { coefficient }\end{array}$ & $\begin{array}{c}\text { Number } \\
\text { of } \\
\text { compared } \\
\text { countries }\end{array}$ \\
\hline & ESI & & EPI & & SATIS & & HAPPY & \\
\hline ESI & 1 & 145 & $.640^{* *}$ & 125 & $.544^{* *}$ & 53 & .161 & 94 \\
\hline EPI & $.640^{* *}$ & 125 & 1 & 131 & $.536^{* *}$ & 53 & $.311^{* *}$ & 94 \\
\hline SATIS & $.544^{* *}$ & 53 & $.536^{* *}$ & 53 & 1 & 57 & $.611^{* *}$ & 57 \\
\hline HAPPY & .161 & 94 & $.311^{* *}$ & 94 & $.611^{* *}$ & 57 & 1 & 102 \\
\hline BROAD & $.465^{* *}$ & 140 & $.646^{* *}$ & 127 & $.472^{* *}$ & 55 & $.447^{* * *}$ & 99 \\
\hline TEL3 & $.349^{* *}$ & 144 & $.526^{* *}$ & 130 & $.284^{*}$ & 57 & $.371^{* *}$ & 102 \\
\hline MOB3 & $.266^{* *}$ & 144 & $.268^{* *}$ & 130 & $.268^{*}$ & 57 & .145 & 102 \\
\hline INT3 & $.426^{* *}$ & 144 & $.565^{* *}$ & 130 & $.538^{* *}$ & 57 & $.431^{* *}$ & 102 \\
\hline Radio & $.405^{* *}$ & 49 & .227 & 42 & .387 & 18 & -.009 & 32 \\
\hline $\mathrm{TV}$ & $.281^{* *}$ & 87 & $.234^{*}$ & 79 & .296 & 35 & .024 & 67 \\
\hline TEL1 & $.265^{*}$ & 62 & .142 & 57 & .129 & 26 & .087 & 47 \\
\hline MOB1 & .228 & 58 & .031 & 53 & 287 & 24 & .081 & 42 \\
\hline COMP1 & $.477^{* *}$ & 105 & $.537^{* *}$ & 102 & $.491^{* *}$ & 48 & $.481^{* *}$ & 86 \\
\hline INT1 & $.445^{* *}$ & 99 & $.557^{* *}$ & 99 & $.391^{* *}$ & 47 & $.540^{* *}$ & 84 \\
\hline СOMP2 & $.536^{* *}$ & 59 & $.621^{* *}$ & 63 & $.463^{* *}$ & 34 & $.578^{* *}$ & 59 \\
\hline MOB2 & $.321^{*}$ & 53 & $.446^{* *}$ & 58 & .208 & 30 & $.338^{*}$ & 54 \\
\hline \multicolumn{9}{|c|}{ **. Correlation is significant at the 0.01 level (2-tailed) } \\
\hline \multicolumn{9}{|c|}{ *. Correlation is significant at the 0.05 level (2-tailed) } \\
\hline Code & \multicolumn{5}{|l|}{ Variable } & \multicolumn{3}{|c|}{ Number of countries } \\
\hline ESI & \multicolumn{5}{|c|}{ Environmental Sustainability Index } & \multicolumn{3}{|c|}{145} \\
\hline EPI & \multicolumn{5}{|c|}{ Environmental Performance Index } & \multicolumn{3}{|c|}{131} \\
\hline SATIS & \multicolumn{5}{|c|}{ Satisfaction with your life } & \multicolumn{3}{|c|}{57} \\
\hline HAPPY & \multicolumn{5}{|c|}{ Feeling of happiness } & \multicolumn{3}{|c|}{102} \\
\hline BROAD & \multicolumn{5}{|c|}{ Fixed (wired)-broadband subscriptions per 100 inhabitants } & \multicolumn{3}{|c|}{150} \\
\hline TEL3 & \multicolumn{5}{|c|}{ Fixed-telephone subscriptions } & \multicolumn{3}{|c|}{155} \\
\hline MOB3 & \multicolumn{5}{|c|}{ Mobile cellular } & \multicolumn{3}{|c|}{155} \\
\hline INT3 & \multicolumn{5}{|c|}{ Individuals Internet } & \multicolumn{3}{|c|}{155} \\
\hline RADIO & \multicolumn{5}{|c|}{ Percentage of households with radio } & \multicolumn{3}{|c|}{52} \\
\hline TV & \multicolumn{5}{|c|}{ Percentage of households with TV } & \multicolumn{3}{|c|}{93} \\
\hline TEL1 & \multicolumn{5}{|c|}{ Percentage of households with fixed line telephone } & \multicolumn{3}{|c|}{67} \\
\hline MOB1 & Percenta & e of house & holds with $\mathrm{m}$ & obile cellu & ar phone & & 62 & \\
\hline COMP1 & Percenta & e of house & holds with ce & mputer & & & 114 & \\
\hline INT1 & Percenta & e of house & holds with in & ternet acce & s at home & & 108 & \\
\hline COMP2 & Percenta & of indivi & duals who us & ed ICTs co & nputer & & 68 & \\
\hline MOB2 & Percenta & e of indivi & luals who us & ed ICTs m & bile & & 61 & \\
\hline
\end{tabular}


There is an on-going discussion about the need to replace GDP as the prevailing measure of life quality with a better indicator [19]. Namely, GDP measures economic activity, which is not necessarily related to useful activity or the quality of life. The quality of life is a rather subjective issue, which is best determined by the individual. Indicators like Happiness in Nations or Life Satisfaction therefore seem to be more appropriate measures. Kahneman and Deaton [16] discovered a clear positive linear correlation between subjective evaluation of life and income at all observed levels of income. There is also a positive correlation between income and emotional wellbeing, however this correlation is weaker with increasing income. From this perspective, both life satisfaction and happiness are good candidates for a replacement of GDP. Life satisfaction seems to be a stronger candidate, because its correlation with income does not depend on the income level. Our analysis in Table 1 also demonstrates that both happiness and life satisfaction are positively correlated with established indicators of sustainability. In addition, they are also positively correlated with most of the observed technological indicators. These observations demonstrate that both Happiness in Nations and Life Satisfaction are good candidates for the leading indicator of life quality in nations.

So far, the main objection in the broader use of Happiness in Nations and Life Satisfaction was the absence of frequent measurements around the world. Both indicators have been measured for decades, however only in some countries and only once every few years. This problem has been addressed recently by Gallup. They introduced the Gallup-Healthways Well-Being Index in 2008, and they survey daily 1,000 US residents with questions about wellbeing and health. In 2012, Gallup and Healthways announced the creation of a global joint venture to expand these measurements of wellbeing globally [20]. This initiative opens new possibilities in implementation of subjective wellbeing indicators, also as a possible replacement for GDP.

In the discussion about subjective wellbeing, it is also important to address the disconnection between political class and ordinary citizens. Although majorities of citizens are often not happy with their leaders, they keep re-electing persons from the political class, whose values are many times strongly disconnected from those of ordinary people [11]. A possible solution to this problem was suggested by the pollster Scott Rasmussen [11] who noticed that the political class is getting more and more irrelevant, and that people rely on decisions made on a local level and that mistakes of the central governments are becoming less relevant to their lives.

In this respect, daily measurement of Happiness in Nations and Life Satisfaction could also be used as a guide to decision making. This could also very clearly demonstrate the effects of political decisions on happiness and satisfaction of citizens, and therefore make the political process more accountable.

Solution to complex problems of contemporary society is obviously not simple. Daily measurement of Happiness in Nations and Life Satisfaction could serve both as a direct measure of life quality as well as a useful tool in the national and local decision making process. Since the current crises are interconnected, it is also important that indicators Happiness in Nations and Life Satisfaction are positively correlated both with GDP and sustainability indicators such as ESI and EPI, as well as with technological development indicators, which are related to the ability of a given society for rapid technological and also economic development. Indicators of happiness and life satisfaction could therefore serve as a common theme between different crises, and focus of policy makers on these indicators could help to overcome the current crises in such a way that would optimize happiness and satisfaction of citizens. 
From this analysis it is clear that Happiness in Nations and Life Satisfaction are simple indicators with a potential to become widely accepted measures of development. For this to happen, it would be helpful that a new societal contract is accepted where self-governance via direct participatory democracy could be one of the essential building blocks. Recent progress in particular in information and communication technology provides tools that could make this vision a reality. In this way negative effects of current political class on the development of the sustainable knowledge society could be removed or at least mitigated. Although the details are impossible to predict with current knowledge, the intertwining of the self-governing free society and rapid technological progress has a potential to contribute toward the building of the new global, abundant and free society.

\section{CONCLUSION}

Although sustainability indicators have been intensively studied in the past decades, there is still no simple and easily measurable index of sustainability that could be directly related to the quality of life of an individual.

Sustainability indicators ESI and EPI, observed indicators of technological development and observed subjective indicators of Happiness in Nations and Life Satisfaction are strongly positively correlated. Among indicators of technological development those related to internet and computers have the strongest correlations with both sustainability and subjective measures of life satisfaction. Happiness in Nations and Life Satisfaction are also excellent candidates to replace GDP as the leading indicator of development upon which important political and economic decisions are based.

\section{NOMENCLATURE}

$\begin{array}{ll}\text { BROAD } & \text { Fixed (wired)-broadband subscriptions per } 100 \text { inhabitants } \\ \text { COMP1 } & \text { Percentage of households with computer HH4 } \\ \text { COMP2 } & \text { Percentage of individuals who used ICTs computer HH5 } \\ \text { EPI } & \text { Environmental Performance Index } \\ \text { ESI } & \text { Environmental Sustainability Index } \\ \text { GDP } & \text { Gross Domestic Product } \\ \text { GNI } & \text { Gross National Income } \\ \text { HAPPY } & \text { Happiness in Nations Indicator } \\ \text { HPI } & \text { Happy Planet Index } \\ \text { INT1 } & \text { Percentage of households with internet access at home } \\ \text { INT3 } & \text { Individuals Internet } \\ \text { MOB1 } & \text { Percentage of households with mobile cellular phone } \\ \text { MOB2 } & \text { Percentage of individuals who used ICTs mobile } \\ \text { MOB3 } & \text { Mobile cellular } \\ \text { RADIO } & \text { Percentage of households with radio } \\ \text { SATIS } & \text { Life Satisfaction Indicator } \\ \text { TEL1 } & \text { Percentage of households with fixed line telephone } \\ \text { TEL3 } & \text { Fixed-telephone subscriptions } \\ \text { TV } & \text { Percentage of households with TV }\end{array}$

\section{REFERENCES}

1. Esty, D.C., Levy, M., Srebotnjak, T., de Sherbinin, A., 2005 environmental sustainability index: benchmarking national environmental stewardship. New Haven: Yale Center for Environmental Law \& Policy; 2005. See also: http://www.yale.edu/esi, [Accessed: 05-February-2014] 
2. Esty, D.C., Levy, M.A., Srebotnjak, T., de Sherbinin, A., Kim, C.H., Anderson, B., Pilot 2006 environmental performance index, New Haven: Yale Center for Environmental Law \& Policy, 2006, See also: http://www.yale.edu/epi, [Accessed: 05-February-2014]

3. Kahneman, D., Development in the measurement of subjective well-being, J. Econ.

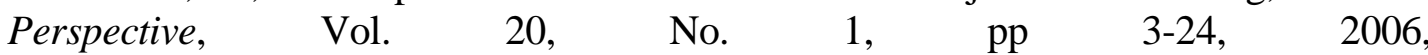
http://dx.doi.org/10.1257/089533006776526030

4. Zidanšek, A., Sustainable development and happiness in nations, Energy, Vol. 32, pp 891-897, 2007, http://dx.doi.org/10.1016/j.energy.2006.09.016

5. Veenhoven, R., World database of happiness, Soc Indicators Res, Vol. 34, No. 3, pp 299-313, 1995; See also: http://www.eur.nl/fsw/research/happiness/, [Accessed: 05-February-2014]

6. Schumpeter, J.A., The Theory of Economic Development: An Inquiry into Profits, Capital, Credit, Interest, and the Business Cycle, Transaction Publishers, 1982.

7. Kondratiev, N. D., The Major Economic Cycles (in Russian). Moscow. 1925; Translated and published as The Long Wave Cycle by Richardson \& Snyder, New York, 1984.

8. Korotayev, A.V., Tsirel, S.V., A Spectral Analysis of World GDP Dynamics: Kondratieff Waves, Kuznets Swings, Juglar and Kitchin Cycles in Global Economic Development, and the 2008-2009 Economic Crisis, Structure and Dynamics, Vol. 4, No. 1, Article 1, 2010, See also: http://www.escholarship.org/uc/item/9jv108xp, [Accessed: 05-February-2014]

9. Kuznets, S.S., Secular Movements in Production and Prices. Their Nature and their Bearing upon Cyclical Fluctuations, Houghton Mifflin, Boston, MA, USA, 1930.

10.United States Department of Agriculture, Economic Research Service, International Macroeconomic Data Set, Historical Real Per Capita (GDP) Values, http://www.ers.usda.gov/data-products/international-macroeconomic-data-set.aspx, [Accessed: 13-March-2014]

11.Rasmussen S.W., In search of self-governance, CreateSpace Independent Publishing Platform, 2010.

12.Lyubomirsky, S., Sheldon K.M., Achieving sustainable gains in happiness: change your actions, not your circumstances, J Happiness Stud, Vol. 7, pp 55-86, 2006, http://dx.doi.org/10.1007/s10902-005-0868-8

13.The Happy Planet Index 2.0, The New Economics Foundation (NEF), 2009, http://www.happyplanetindex.org/, [Accessed: 05-February-2014]

14.Jeremy Bentham, An Introduction to the Principles of Morals and Legislation, London, 1789.

15.Inglehart R., Foa R., Peterson C., Welzel C., Development, Freedom, and Rising Happiness, Perspectives on Psychological Science, Vol. 3, pp 264-285, 2008, http://dx.doi.org/10.1111/j.1745-6924.2008.00078.x

16.Kahneman D., Deaton A., High Income Improves Evaluation of Life But Not Emotional Well-Being, Proceedings of the National Academy of Sciences, Vol. 107, No. 38, pp 16489-16493, 2010.

17.World Values Survey, Happiness and Life Satisfaction, http://www.wvsevsdb.com/wvs/WVSAnalize.jsp, [Accessed: 01-August-2013]

18.ITU World Telecommunication/ICT Indicators Database, Selected indicators on technological http://www.itu.int/en/ITU-D/Statistics/Pages/stat/default.aspx, development, 01-August-2013], see also http://www.idc.com/groups/isi/main.html, [Accessed: 01-August-2013]

19.Costanza, R., Kubiszewski, I., Giovannini, E., Lovins, H., McGlade, J., Pickett, K.E., Ragnarsdóttir K, Roberts D, De Vogli R, Wilkinson R., Time to leave GDP behind, Nature, Vol. 505, No. 7483, pp 283-285, 2014, http://dx.doi.org/10.1038/505283a 
20.Gallup-Healthways Solutions, http://www.healthways.com/solution/default.aspx, [Accessed: 18-April-2014]

Paper submitted: 13.03.2014

Paper revised: 19.04.2014

Paper accepted: 19.04.2014 